E3S Web of Conferences 1, 14003 (2013)

DOI: $10.1051 / \mathrm{e} 3$ sconf/20130114003

(c) Owned by the authors, published by EDP Sciences, 2013

\title{
Nanosilver emissions to the atmosphere: a new challenge?
}

\author{
T. Walser ${ }^{1}$, F. Schwabe ${ }^{2}$, L. Thöni ${ }^{3}$, L. De Temmerman ${ }^{4}$ and S. Hellweg ${ }^{1}$ \\ ${ }^{1}$ Institute of Environmental Engineering, ETH Zurich, Zurich, Switzerland, tobias.walser@ifu.baug.ethz.ch \\ ${ }^{2}$ Soil Protection Group, ETH Zurich, Zurich, Switzerland, franziska.schwabe@env.ethz.ch \\ ${ }^{3}$ Research Group for Environmental Monitoring (FUB), Rapperswil, Switzerland, lotti.thoeni@fub-ag.ch \\ ${ }^{4}$ Veterinary and Agrochemical Research Centre, Tervuren, Belgium, ludwig.detemmerman@coda-cerva.be
}

\begin{abstract}
Atmospheric deposition of silver in Switzerland decreased significantly between 1995 and 2010, but recent increases in nanosilver production present a potentially new emission source of silver. 'While nanosilver is usually integrated in a robust matrix and its release is either controlled, dampened (highly diluted silver in nanosilver textiles) or prevented (computer modules), point source emissions of nanosilver can occur at the manufacturing sites. The emission of nanosize particles of particular concern because these particles penetrate deeply in the lungs, and have the potential of causing long-term adverse effects to humans. We investigated local silver emission patterns with bryophytes Brachythecium rutabulum and Hypnum cupressiforme and with bulk (dry and wet) deposition measurements of silver, using Bergerhoff samplers, close to a nanosilver manufacturer. With mean values of $0.033 \mu \mathrm{g} \mathrm{g}^{-1}$, the silver concentrations in the mosses were the same as the background concentration of Switzerland (141 sites). The spatial distribution revealed a decrease in the silver concentrations in moss as a function of increasing distance from the nanosilver manufacturer. The monthly collected bulk depositions were higher in the area of nanosilver production $\left(0.175 \pm 0.13 \mu \mathrm{g} \mathrm{m}^{-2}\right.$ day $\left.^{-1}\right)$ in comparison to rural $\left(0.105 \pm 0.08 \mu \mathrm{g} \mathrm{m}^{-2}\right.$ day $\left.^{-1}\right)$ and urban areas $\left(0.113 \pm 0.05 \mu \mathrm{g} \mathrm{m}^{-2}\right.$ day $\left.^{-1}\right)$ of Eastern Switzerland. Contrary to other areas, the larger monthly variability of the deposition values close to the production site points towards highly variable silver emissions. Subtraction of the silver background deposition results in approximately $60 \mathrm{~g}$ deposited silver per year within a perimeter of $4 \mathrm{~km}$ from the nanoparticle manufacturer. Along with bulk deposition of silver, we also studied potential morphological changes of the deposited nanosilver. We found silver nanoparticles in the form of environmentally stable silver iodide. We conclude that the applied methods are suitable for monitoring nanometal deposition. Dry nanoparticle production processes can generate atmospheric nanoparticle emissions but they appeared to be small in our investigated case.
\end{abstract}

Key words: Silver, nanoparticles, biomonitoring, deposition, bryophytes

\section{Introduction}

In this study, we focus on anthropogenic (nano)silver emissions to the environment. Historically, the photoindustry was the predominant source of silver emissions, with the waste water being the main pathway to the environment (Blaser et al., 2008). Nowadays, silver emission sources are more diverse: The photographic industry is responsible for no more than $8 \%$ of the total use, while electronics and catalyst industry together make up 55\% of the use, ahead of jewelry \& silverware $(25 \%)$ (The Silver Institute, 2011). A minor share (0.5\%) of the silver used is incorporated in biocidal products. This value translates into about 28 tons of silver used in Europe, whereas 3.8 tons are applied to textiles, including species such as silver salts (79\%), bulk (nano)silver metal (13\%), and silver glasses and silver zeolites (8\%) (Burkhardt et al., 2011). For Switzerland, these values can be estimated as $120 \mathrm{~kg}$ silver discharged to waste water and $40 \mathrm{~kg}$ disposed in incineration plants (Burkhardt et al., 2011). However, few nanosilver pathways have been investigated so far, such as the measured silver release into waste water (Kaegi et al., 2011). While indoor emissions from nanoparticle production processes can be measured 
with commercial devices, nanoparticle emissions from production processes to the outdoor environment are yet to be studied. The growing concern over atmospheric deposition of heavy metals has led to an increase of the use of mosses to estimate deposition levels on continental (Harmens et al., 2008), country, regional, but also less frequently - on local scale (Bargagli, 1998). Detailed reviews can be found in (Tessier et al., 1999; Onianwa, 2001; Zechmeister et al., 2003). As non-vascular plants, bryophytes accumulate metals from the air. They often show a high toxitolerance. Moreover, there is a correlation between accumulation and input to the ecosystem, e.g. (Berg et al., 1997). Thus, mosses can be used as bioindicators, also for (nano)silver (Thöni et al., 1996). Nanosilver emissions are of environmental concern because of the high antimicrobial activity of released silver ions and the still unclear additional toxic action of the silver nanoparticles (Wijnhoven et al., 2009). Data on silver concentrations in mosses are available for Switzerland from 1995 (Thöni et al., 2008) and 2010 (data not yet published). In view of the growing nanosilver industry, it is of increasing importance to know the background level of silver in the ecosystem in order (i) to evaluate the current state of contamination, (ii) to control the evolution over time, and (iii) to predict the incidence of possible future silver emissions in order to establish the necessary interventions. Hence, additional measurement campaigns are required, taking into account the speciation of the nanosilver. Specific attention has to be paid to local pollution sources in order to take action at an early stage, if necessary.

The aims of this study were (i) to quantify silver deposition in the immediate surroundings of a nanosilver production company, in terms of concentration in mosses as well as by measured deposition rates, (ii) to analyze spatial deposition patterns with increasing distance from the potential emission source, (iii) to investigate the morphology of the detected silver nanoparticles, (iv) to compare and assess historical silver concentrations with current silver concentrations in Switzerland, and (v) to put the results into the context of current (nano)silver flows in Switzerland.

\section{Materials and Methods}

The investigations of the morphology and elemental composition of the primary and secondary nanoparticles were performed by means of a Transmission Electron Microscope (TEM, Tecnai F30, FEI; field emission gun; SuperTwin lens; resolution ca. $0.1 \mathrm{~nm}$; additionally equipped with an energy-dispersive X-ray spectrometer (EDXS) for qualitative elemental analyses). Moss leaves were analyzed with scanning electron microscopy (SEM, FEI Quanta Q200), which allowed the investigation of heavy metals on the surface of the mosses. The primary nanoparticles were also characterized by their size (Fig.4). In the field work, we collected the pleurocarp moss species Hypnum cuprressiforme Hedw.sl and Brachythecium rutabulum (Hedw.) Bruch, Schimp. \& Gümbel at 8 sites within a radius of $<1 \mathrm{~km}$ from the nanoparticle production company (Fig.1). Three more samples were taken $1-10 \mathrm{~km}$ from the potential silver emission source. The mosses were collected from the ground or on surfaces of

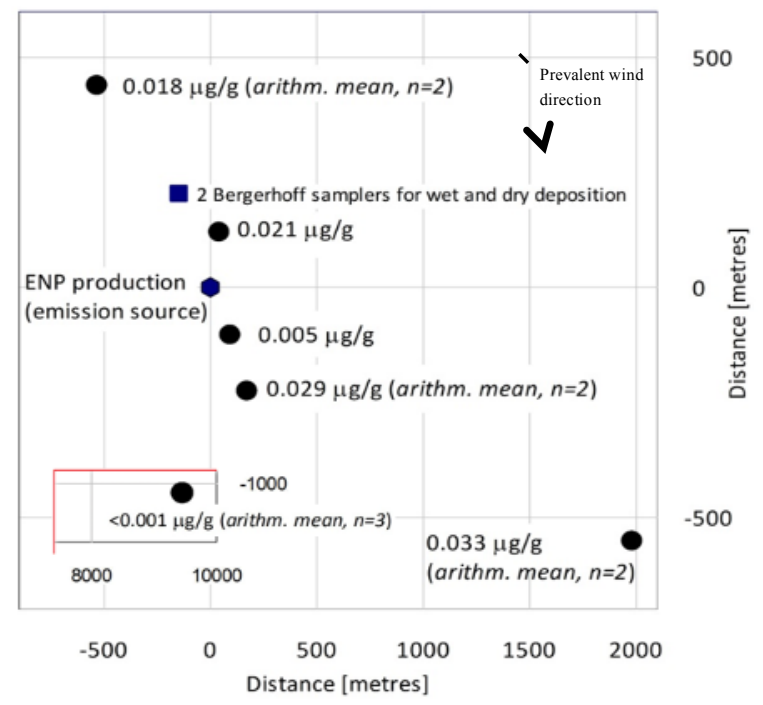

Figure 1. Sampling grid of the mosses in the area of the nanoparticle production firm. The concentrations values indicate silver mass per dry mass of moss.

decaying stumps, at least $5 \mathrm{~m}$ away from the nearest tree. Long-term weather data (wind, rain) for the particular location were taken into consideration. In addition to the local field campaign, the silver monitoring in Switzerland was continued by collecting mosses in 2010 at the same 141 sites as in the previous monitoring period (1995, approximately five moss samples per $1000 \mathrm{~km}^{2}$ ) in order to account for the background concentration as well as for the trend in silver deposition.

The moss samples were cleaned, and the stems of the last three years' growth removed. Then, this plant material was digested in a high pressure microwave oven, with concentrated $\mathrm{HNO}_{3}$ and $\mathrm{H}_{2} \mathrm{O}_{2}$, for further analysis with ICP-MS (Varian 920). Zero controls and comparisons to reference materials were carried out for quality control.

In addition to the deposition measured by examining the mosses, we measured the bulk (dry and wet) silver deposition with the Bergerhoff (Verband Deutscher Ingenieure, 2010) in 1994 (Thöni, 1999) and 2008 at 5 sites sampled quarterly across Eastern Switzerland. In addition, we installed two Bergerhoff samplers close to a nanosilver production site over a 1 year period with monthly change of the sampling devices.

\section{Results and Discussion}

The primary particles consisted of $80 \%$ silica and $20 \%$ evenly distributed nanosilver with a size mode of $30 \mathrm{~nm}$ (Fig. 4). The nanoparticle production company is the only relevant source of atmospheric silver emissions in the investigated area. Hence, we assume that any significant increase in silver around the production site would be caused by that firm. Silver concentrations in the mosses were between 0.002 and $0.033 \mu \mathrm{g} \mathrm{g}^{-1}$ (Fig. 1, 3). The silver concentration at the sampling point $>8 \mathrm{~km}$ away from the production facility was below the quantification limit of $0.001 \mu \mathrm{g} \mathrm{g}^{-1}$, indicating that the silver concentrations decrease with increasing distance from the production firm. We found higher silver concentrations in the prevalent wind direction. The bulk deposition rate of airborne silver was between $0.04 \mu \mathrm{g} \mathrm{d}^{-1}-0.44 \mu \mathrm{g} \mathrm{d}^{-1}$ 
$\mathrm{m}^{-2}$ (Fig. 2) with an average value of $0.175 \pm 0.088 \mu \mathrm{g} \mathrm{d}^{-1}$ $\mathrm{m}^{-2}(95 \% \mathrm{CI})$. The monthly fluctuations of silver deposition were not correlated with the total dust deposition and the measured silver deposition showed a high variability (data not shown). These facts point towards a discontinuous silver emission source. Moreover, the average silver deposition was higher around the nanoparticle production site, but in the same order of magnitude as other areas of Switzerland $\left(0.108 \pm 0.0298 \mu \mathrm{g} \mathrm{d}^{-1} \mathrm{~m}^{-2}(95 \% \mathrm{CI})\right.$. In contrast, regarding the silver accumulation in the mosses, the silver concentrations did not differ significantly between the nanoparticle production area and other regions of Switzerland. From a temporal perspective for the entire area of Switzerland, we observe decreasing silver concentrations in mosses between 1995 and 2010 (Fig.3)
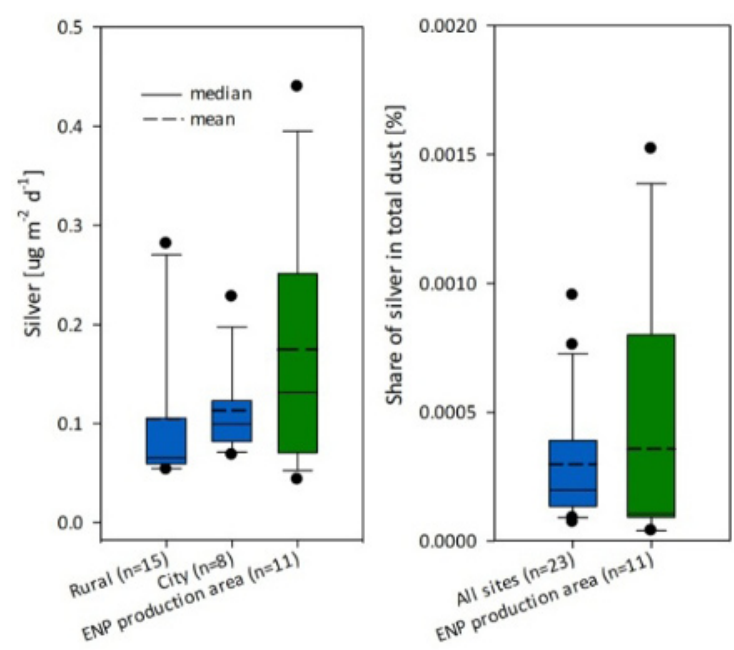

Figure 2. Left: Absolute (wet and dry) silver deposition close to the nanoparticle factory (monthly measurements). The results are shown together with absolute deposition values for rural and city sites in Switzerland. Right: The share of silver in the dust is higher around the production area in comparison to other areas in Switzerland.

The analysis with electron microscopy showed nanosilver particles of $80 \mathrm{~nm}$ diameter in the form of the environmentally stable silver iodide (Fig. 4). Not only the physical and chemical form, but also the total amount of deposited nanosilver is of interest for environmental fate and risk modeling. For the calculations, we took into account the estimated travel distance of the particles:

$$
d_{99 \%}=h_{e} \cdot v_{w}^{-1} \cdot \frac{\rho_{p} d_{p}^{2} C_{c} g}{18 \mu}
$$

$d_{99 \%}=$ distance, where $99 \%$ of emitted particles are assumed to be deposited; $\mathrm{h}_{\mathrm{e}}=$ height of emission source; $v_{W}=$ average wind speed; $\rho_{p}=$ particle density; $d_{p}=$ particle diameter; $C_{c}=$ slip correction factor; $g=$ gravity; $\mu=$ viscosity of air

We subtracted the silver background deposition and obtained the total silver deposition in the circle area within $d_{99 \%}\left(4 \mathrm{~km}, 9.1 \cdot 10^{-5} \mu \mathrm{g} \mathrm{m}^{-2} \mathrm{~d}^{-1}\right)$ from the nanoparticle production firm with the integral below and the known

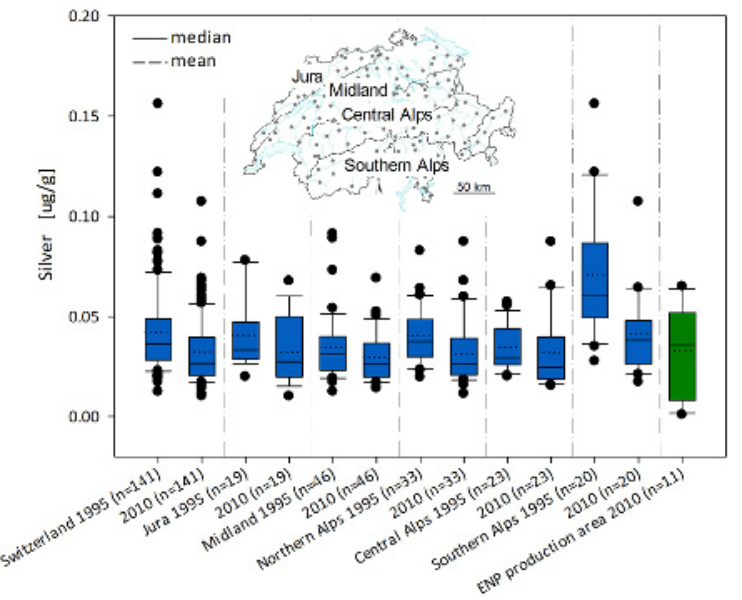

Figure 3. Silver concentrations in the mosses for Switzerland and further specified for different regions (blue). For comparison the silver concentrations in the moss around the nanoparticle production site (green). The Swiss map shows the sampling locations and

deposition value close to the emission source $d_{e}(0.067$ $\left.\mu \mathrm{g} \mathrm{m}^{-2} \mathrm{~d}^{-1}\right)$ :

$$
\int_{d_{e}}^{d_{99}} a \cdot e^{-b x} d x
$$

With the values $a=0.067 \mu \mathrm{g} \mathrm{m}^{-2} \mathrm{~d}^{-1}$ and the optimized value $b=0.00165$, the estimation is valid for a total area of $50 \mathrm{~km}^{2}$ where $99 \%$ of the silver deposition occurs. Solving the integral results in $60 \mathrm{~g}$ deposited silver per year.

\section{Conclusions}

Even though we did not observe increased silver concentrations in the bryophytes, the bulk silver deposition is elevated around the ENP production site in comparison to urban and rural areas in Switzerland. Hence, dry synthesis of nanosilver can lead to emissions to the atmosphere. However, the annual atmospheric silver deposition to the soil is small in view of the total soil content. The Earth's crust contains approximately $0.1 \mu \mathrm{g} \mathrm{g}^{-1}$ of silver and soils contain approximately $0.3 \mu \mathrm{g} \mathrm{g}^{-1}$ (Turekian et al., 1961). Moreover, the observed silver deposition rates in the vicinity of the nanoparticle production plant are in the same order of magnitude as in the background. However, the bioavailable fraction of the engineered nanoparticles might be higher than the natural background. Hence, nanoparticles from anthropogenic origin in ambient air or water are likely to be more problematic than those originating from bedrock, with slow weathering. From this perspective and by embracing the precautionary principle, a safe handling of engineered nanoparticles implies the complete prevention of nanoparticle emissions to the indoor and outdoor environment.

\section{Acknowledgement}

Eva Seitler, Norbert Schnyder, Silvia Marty (all FUB); OSTLUFT for making available the Bergerhoff samples of 2008; Frank Krumeich (Electron microscopy center of 
ETH Zurich; Björn Studer (ETH Zurich). Funding from 'Prosuite', a research project under the Seventh Framework Program of the European Commission (Reference number 227078), is gratefully acknowledged.

\section{References}

Bargagli R. Trace elements in terrestrial plants / An ecophysiological approach to biomonitoring and biorecovery. Springer, Berlin, Heidelberg, NY, 1998, $324 \mathrm{p}$.

Berg T, Steinnes E. Use of mosses (Hylocomium splendens and Pleurozium schreberi) as biomonitors of heavy metal deposition: From relative to absolute deposition values. Environmental Pollution 1997; 98: 61-71.

Blaser SA, Scheringer M, MacLeod M, Hungerbühler K. Estimation of cumulative aquatic exposure and risk due to silver: Contribution of nano-functionalized plastics and textiles. Science of The Total Environment 2008; 390: 396-409.

Burkhardt M, Englert A, Iten R, Schärer S. Entsorgung nanosilberhaltiger Abfälle in der Textilindustrie Massenflüsse und Behandlungsverfahren. Bundesamt für Umwelt (BAFU), Bern, Rapperswil. 2011, 33.

Harmens H, Norris D. Spatial and temporal trends in heavy metal accumulation in mosses in Europe (1990-2005). 2008,

Kaegi R, Voegelin A, Sinnet B, Zuleeg S, Hagendorfer H, Burkhardt M, Siegrist H. Behavior of metallic silver nanoparticles in a pilot wastewater treatment plant. Environmental Science \& Technology 2011; in press.

Onianwa PC. Monitoring atmospheric metal pollution: A review of the use of mosses as indicators. Environmental Monitoring and Assessment 2001; 71: 13-50.

Tessier L, Boisvert JL. Performance of terrestrial bryophytes as biomonitors of atmospheric pollution. A review. Toxicological \& Environmental Chemistry 1999; 68: 179-220.

The Silver Institute. World silver survey 2011. http://www.silverinstitute.org/supply_demand.php, 2011, 11.

Thöni L. Testing the Bergerhoff method to determine the bulk deposition loads of 49 elements. Atmospheric Environment 1999; 33: 337-344.

Thöni L, Schnyder N, Krieg F. Comparison of metal concentrations in three species of mosses and metal freights in bulk precipitations. Analytical and bioanalytical chemistry 1996; 354: 703-708.

Thöni L, Matthaei D, Seitler E, Bergamini A. Deposition von Luftschadstoffen in der Schweiz. Moosanalysen 1995-2005. Bern. 2008, 150.

Turekian KK, Wedepohl KH. Distribution of the elements in some major units of the Earth's crust. Geological Society of America Bulletin 1961; 72: 175-192.

Verband Deutscher Ingenieure. Messung atmosphärischer Deposition, Bestimmung des Staubniederschlags nach der Bergerhoff-Methode; VDI 4320, 2, VDI 2267, 15. 2010,

Wijnhoven S, Peijnenburg W, Herberts C, Hagens W, Oomen A, Heugens E, Roszek B, Bisschops J, Gosens I, Van De Meent D, Dekkers S, De Jong W, van Zijverden M, Sips A, Geertsma R. Nano-silver - a review of available data and knowledge gaps in human and environmental risk assessment. Nanotoxicology 2009; 3: 109-138.

Zechmeister HG, Grodzińska K, Szarek-Łukaszewska G. Chapter 10: Bryophytes. In: B.A. Markert AMB, Zechmeister $\mathrm{HG}$, editors. Trace metals and other contaminants in the environment. Elsevier, 2003, pp. 329-375.

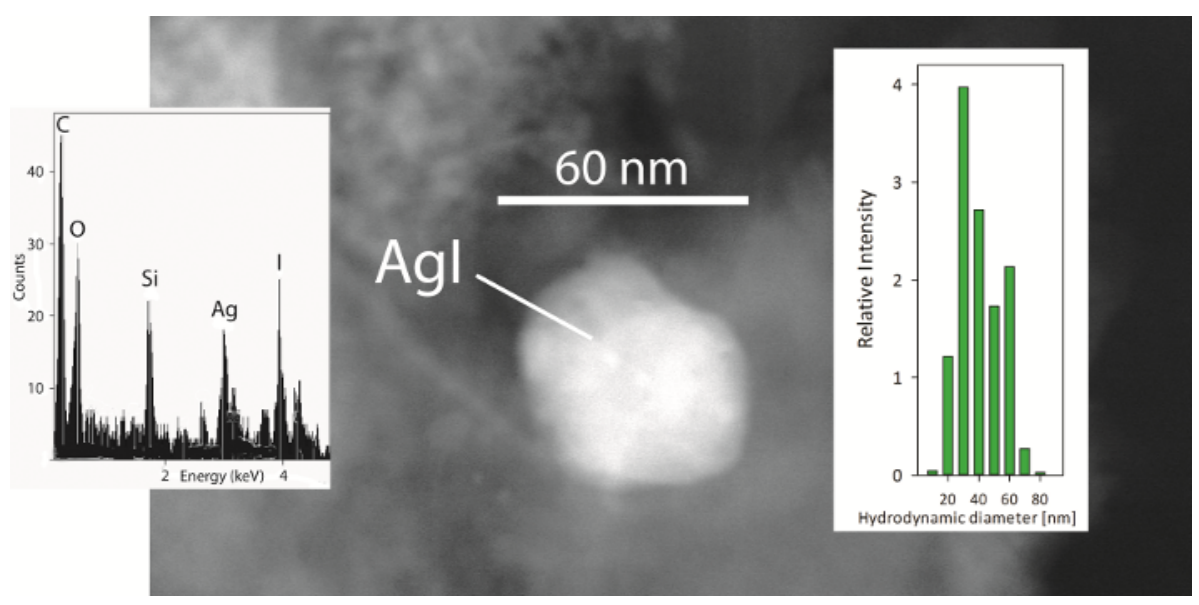

Figure 4. Nanosize silver iodide as detected in the deposited dust (TEM and EDXS). The inlet on the left shows the EDXS results while the inlet on the right shows the size distribution of the primary silver nanoparticles, embedded in a silica matrix. 